\title{
THE DIAGNOSIS OF DISEASES OF THE PANCREAS, WITH SPECIAL REFERENCE TO DIASTASE IN THE URINE
}

\author{
By R. L. MACKENZIE WALLIS \\ (From the Laboratory of Chemical Pathology, Pathological Department, \\ St. Bartholomew's Hospital, London)
}

\section{Introduction.}

THe importance of the pancreas for the maintenance of life has been known for a long time, but it is only in recent years that its place in medicine and surgery has been clearly recognized. The methods of diagnosis of diseases of this gland have so far not been worked out, and this phase of the problem may still be regarded as in its infancy. In view of the manifold functions of the pancreas, and their vital necessity for the economy of the body, it behoves us to use every means available to determine the possible nature and extent of the commoner diseases to which it is prone. It is clear from this very multiplicity of function that not one but several tests must be applied in any given case before a conclusion can be reached as to whether the pancreas is diseased or not. The object of this paper is to describe the various tests for functional activity of the pancreas, and to attempt to appraise their individual or collective worth in diagnosis. The observations have extended over a period of years, and practically all the known tests have received an extended trial. No new tests have been devised, but simply modifications in technique, which have suggested themselves as the work progressed, have been introduced into the various methods.

The Schorstein Lecture delivered by Sir Archibald Garrod (1) gives a complete and excellent survey of the work done, and the writer would here express his indebtedness to his teacher, Sir Archibald Garrod, for much valuable help and encouragement. This work owes its inception to his stimulating influence, and this influence is exemplified in every page of the present paper. The same conclusions have been arrived at, and needless to say the results have been discussed, and additional weight added thereto by such support and advice so freely given.

\section{The Physiology and Biochemistry of the Pancreas.}

There is no organ of the body where such a marked disparity exists between its well-established physiological importance and our powers of estimating its

[Q. J. M., Oct., rgao.] 
functional capacity in clinical medicine. The pancreas possesses two functions of the greatest importance to the maintenance of metabolism, firstly as a digestive organ, and secondly as an organ providing an internal secretion, which controls carbohydrate metabolism.

The true functions of the gland were only established in the last century, and we owe this to a group of great experimental physiologists, particularly Claude Bernard and his school. They established the fact that the secretion from the pancreas contains ferments for the digestion of all three classes of food-stuffs, the proteins, the carbohydrates, and fats. In the latter half of the century the association of the pancreas with diabetes mellitus was clearly expounded by von Mering and Minkowski $\left(1^{*}\right)$. The discovery that total extirpation of the pancreas leads to diabetes mellitus was an epoch-making discovery, and led to the conception of an internal secretion, which in some way controlled carbohydrate metabolism.

Since this discovery of these two main functions an immense amount of detailed work has pervaded the literature, but delve into the subject where you will, abundant evidence of the vast difficulties that beset the study of the pancreas will be forthcoming.

Patholngists, however, have fallen far behind in this march of progress and comparative rapid acquisition of knowledge, but they have not been so favourably placed, chiefly on account of the difficulties of experimental work and the inconclusive morbid anatomical findings. Numerous tests have been devised, based upon the known functions of the gland, but the tendency of each individual worker has been to confine himself to one or two functional tests to the exclusion of all others. That this has met with failure is well known, and is further emphasized by reference to the cases described in this paper. It would appear that hitherto no one has attempted to apply all the various functional tests in any one case of suspected disease of the pancreas, and then to sum up the evidence obtained and clearly state their individual or collective value. This is the object of the present communication. The second object, and, strictly speaking, the primary one, was to ascertain, if possible, whether any light could be thrown on the causation of diabetes mellitus. The recent work of Allen in America affords very strong evidence for implicating the pancreas. In my work it is to be regretted that so far no evidence of disturbance of function has been detected, but the results have given an insight into the possible site of disease so that the negative evidence becomes of real value. The conception of a definite balance of function between the various ductless glands leads one to speculate that the pancreas may be at fault, because it fails to balance its secretion against one of the other glands. The results with the Loewi adrenalin mydriasis test are of particular interest in this connexion, and will be referred to later in this paper. 


\section{Clinical Features.}

The clinical diagnosis of diseases of the pancreas is of the greatest importance, and necessarily occupies the first place in any discussion of its commoner affections. From the point of view of the clinician this is a matter of some difficulty. We might almost introduce a medical aphorism in the clinical diagnosis of diseases of the pancreas- 'it is easy to forget the pancreas, but still more difficult to remember it.' The physician who remembers the pancreas when confronted with certain well-defined clinical features, and places it under suspicion, has the satisfaction of seeing his diagnosis confirmed, and frequently with great benefit to his patient. By inspection, palpation, blood examination, and a careful study of the symptoms, particularly lumbar pain, tenderness, the presence of a tumour, and presence of pressure effects on neighbouring viscera, he obtains valuable data, and these have to be assessed at their true value. Features, such as jaundice, wasting, and anaemia may obscure the diagnosis, more particularly when we realize that it is rarely that the pancreas is alone involved. Of the symptoms, epigastric pain and tenderness would appear to be the most common, usually deep-seated, and radiating upwards to the right shonlder. The wasting and anaemia which are frequent concomitants can be explained by the defieiency of pancreatic ferments, and consequently lack of assimilation of digested foodstuffs from the alimentary canal. This deficiency also accounts for the large and bulky stools, and their characteristic appearance, which is likened to finelydivided asbestos, but often described as clay-coloured. The urinary changes are not very characteristic, but the presence of glycosuria may shed a ray of light on an otherwise obscure case, and the presence of bile pigments in quantity will point to involvement of the common bile duct. The occurrence of oxaluria has been suggested as characteristic of pancreatic diseases, but although frequently present it cannot be said that it is in any way. an indication of pancreatic insufficiency. It is much more likely to be due to the associated intestinal changes secondary to abnormal digestion in the alimentary canal. The same applies to indicanuria.

In assessing the value of the clinical data it must be clearly recognized that some functions of the pancreas may be subserved by other organs when the former is diseased, and again one or more functions may be disturbed, leaving the others quite unaffected. Bearing these points in mind the clinician is able to gain much valuable and useful information, which can be applied to the diagnosis and treatment of his patient, with mutual gain to all concerned. Finally, we have the opportunity of advising exploratory laparotomy as a valuable. aid, and often an indispensable adjunct in the present state of our knowledge. 
IV. The Methods used for testing the Functional Activity of the Pancreas.

The tests so far devised depend entirely on the two chief functions of the pancreas-the digestion of food-stuffs in the intestine, and the internal secretion controlling carbohydrate metabolism. In discussing the tests, therefore, it is convenient to consider them under these two headings, and since the digestive functions are more easily determined, it follows that the tests under this heading are more numerous, and consequently have received considerably more attention. A full description of these tests has been given by Sladden $(14,15)$ in two valuable papers, and the reader is referred to these for information upon the subject.

1. Tests for the digestive ferments secreted into the alimentary canal, and depending upon a diminution or complete absence of these ferments. Most of these tests have necessarily to be carried out on the stomach contents, or the faeces.

(a) Azotorrhoea. With the associated creatorrhoea, combining the Schmidt test, the Kashiwado modification of the former (3), the Sahli test, and the tryptic activity of the faeces by the serum agar plate method, and the casein method of Gross:

(b) Steatorrhoea. Including analysis of the fat content of the faeces, the 'sajodin' test of Winternitz (7), and tests for lipolytic activity of the faeces.

(c) Diastase. The presence of microscopical starch in the faeces, and the diastatic index of the faeces.

(d) The oil-test breakfast, combining the estimation of all thiree digestive ferments.

2. Tests depending upon other functions of the pancreas:

(a) The general characters of the urine.

(b) The diastase content of the urine $(8,9)$.

(c) The Cammidge pancreatic reaction (10).

(d) The Loewi adrenalin mydriasis reaction (11).

(e) The glucose tolerance test.

The pancreas being the only gland in the body which furnishes an enzyme for each class of food-stuff, it would appear possible to apply digestion tests to ascertain whether there is any marked deficiency in one or all of these three ferments. In practice, however, it is much more difficult than at first appears, especially when we attempt to estimate clinically its functional capacity. The ferments undergo considerable modifications in their passage through the alimentary canal, and we meet with additional difficulties due to the presence of erepsin, a protein-digesting ferment in the small intestines, and last but by no means least considerable bacterial fermentation. Further, we cannot control the duration of passage of the gastro-intestinal contents, and if this is either increased or delayed the composition of the faeces is thereby considerably altered. All that we can do is to adopt precautions, and consider all' possible fallacies, so as to avoid sources of grave error in the results. 
To control the composition of the faeces a standard diet has been adopted, based largely upon that devised by Schmidt. This diet yields residues which are sufficiently characteristic, and there is the additional advantage that we have abundant normal controls with which a comparison can be made. The diet consists of 2 eggs, $1 \frac{1}{2}$ litres of milk, $100 \mathrm{grm}$. of toast, $50 \mathrm{grm}$. of butter, $125 \mathrm{grm}$. of raw beef, $190 \mathrm{grm}$. of potatoes, and $80 \mathrm{grm}$. of oatmeal. This diet contains about $102 \mathrm{grm}$. of protein, $111 \mathrm{grm}$. of fat, $191 \mathrm{grm}$. of carbohydrate, and yields about 2,234 calories of energy. In hospital practice the constituents of the diet are spread out over the day in the following routine order :

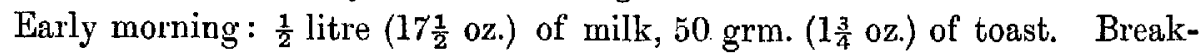
fast, 9 a.m.: $\frac{1}{2}$ litre ( $17 \frac{1}{2}$ oz.) of oatmeal gruel made from 40 grm. ( $1 \frac{1}{2}$ oz.) of

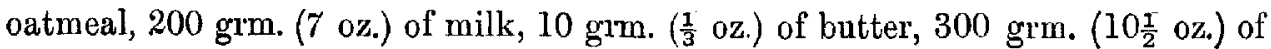
water, and 1 egg added.

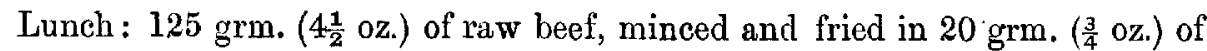
butter, $250 \mathrm{grm}$. (9 oz.) of mashed potato made from $190 \mathrm{grm}$. $(7 \mathrm{oz}$.$) of mashed$ potato, $100 \mathrm{grm}$. ( $3 \frac{1}{2} \mathrm{oz}$.) of milk, and $10 \mathrm{grm}$. ( $\frac{1}{3} \mathrm{oz}$.) of butter.

Tea: exactly the same as the early morning meal.

Supper: the same as taken at breakfast.

This diet is very simple and can be easily adopted in the hospital wards, and it is only rarely that we find the patient is unable to take it. If milk does not agree cocoa is substituted, and this is made up as follows : $20 \mathrm{grm}$. ( $\left(\frac{2}{3}\right.$ oz. $)$ of cocoa powder, $10 \mathrm{grm}$. ( $\frac{1}{3} \mathrm{oz}$.) of sugar, $400 \mathrm{grm}$. (14 oz.) of water, and $100 \mathrm{grm}$. (3 oz.) of milk. Previous to the adoption of this diet the patient is given a purgative, and usually after two days of the diet a representative specimen of the faeces can be obtained, but no fixed rule can, of course, be laid down as particular cases are found to vary in this respect.

The bulkiness of the stools is an important feature, and one which can be readily judged by this special diet. Normally, the averago weight of the dried faeces is about $55 \mathrm{grm}$, with a maximum of $62 \mathrm{grm}$. and a minimum of $45 \mathrm{grm}$. A marked rise in the total dried weight is therefore of importance.

The tests applied to the faeces obtained on such a diet necessarily resolve themselves into determining ferment activities. Unfortunately, we bave no means of collecting pure pancreatic juice as it flows down the pancreatic duct, but it should be borne in mind that about one pint or even more of this pancreatic juice pours through the ampulla of Vater into the duodenum every day. This secretion, which is alkaline, and contains quantities of alkaline salts, will necessarily modify the composition of the faeces quite apart from any digestive changes which may have taken place. This is the reason why an estimation of the inorganic ash in the faeces is always carried out, since very low values are almost constantly present when there is complete obstruction to the pancreatic duct and also the common bile duct.

(a) Azotorrhoea and Creatorrhoea. The pancreas supplies the precursor of the ferment trypsin, which is capable of digesting proteins and peptones with the production of amino acids in a form suitable for absorption into the blood- 
stream. In the absence of pancreatic juice from the intestine such proteins, or their partially digested products, escape digestion to a large extent, and pass out in the faeces in an unchanged condition.

The chief nitrogenous fraction of an ordinary diet is meat, and it follows that in the absence of trypsin this will escape complete digestion, and evidence will not be wanting of its presence in the faeces in a recognizable form. A simple microscopical preparation is all that is required to demonstrate the presence of undigested muscle fibres. They may be recognized by their abundance, the yellow colour, the characteristic striations, and possibly the presence of nuclei. This phenomenon is known as creatorrhoea, and is a most valuable sign of pancreatic insufficiency. If a film preparation is made from the faeces of a normal healthy individual on the special diet, only one or two muscle fibres will be seen in each field, or perhaps none at all, and those actually found will be devoid of shape and striations.

The tests of tryptic activity may be regarded as a useful aid, but are certainly not absolute in their indications, and serve to establish the main view adopted in this paper that no one test can be positively relied upon. A positive result showing the absence of trypsin from the alimentary tract is, of course, much more valuable than a negative result, as with every other test so far devised.

(b) Steatorrhoea. The association of the so-called 'fatty stools' with disease of the pancreas has been recognized for a long time, and it is often this phenomenon which calls the attention of the physician to the nature of the case. Frequently it can be recognized by the naked eye; often by simple microscopical examination, especially if iodine is used as a stain; but in cases where the fat is finely divided only by careful chemical analysis. The presence or absence of bile from the intestine, however, produces profound modifications of the fat content, and so must always be taken into account.

Unfortunately we rarely find such 'clean-cut' results in cases of pancreatic insufficiency, and this is partly due to deficiencies in our methods of analysis. The presence of urobilin is always looked for and the most delicate tests applied. Extraction with amyl alcohol of a portion of the stools and treatment of the extract with a fresh alcoholic solution of zinc acetate are always used. The absence of a trace of colour, fluorescence, and the characteristic absorption band of urobilin when examined spectroscopically, conclusively proves that no bile is entering the intestine.

The analysis of the various forms of fat in the stools is carried out on representative samples of the dried faeces, using the Soxhlet method of extraction. The analysis of the faeces involves the adoption of a complex technique, but in order to draw any definite conclusions data as regards the following fractions must be obtained :

(1) The total percentage of fat in the dried faeces.

(2) The percentage of unsplit or neutral fat.

(3) The percentage of free fatty acids.

(4) The percentage of soaps. 
The figures for 3 and 4, therefore, give the total amount of split fat in the faeces. The ratio of these two figures to the total fat gives an indication of the efficiency of the pancreatic secretion as regards its lipolytic activity. This method has been followed throughout the present research, and the results obtained have fully justified the time and labour involved.

The sajodin test of Winternitz (7) has also received an extended trial, but the results have been very disappointing. The object of this test is to administer iodine containing fats, and to detect the liberated iodine in the urine about five hours after ingestion. The best iodine containing fat for this purpose is that known as 'sajodin', which is chemically the calcium salt of iodo-behenic acid. The procedure I have adopted is to give one tablet of 'sajodin' containing $7 \frac{1}{2}$ grains of the salt either with or immediately following a good meal. In two normal healthy individuals, including the writer, iodine appeared in the urine three to five hours afterwards, the total amount being entirely eliminated within one hour of its first appearance. In several cases of undoubted pancreatic disease, no iodine was found in the urine even forty-eight hours after administration. The sajodin, however, requires the presence of bile salts before it can be acted upon by the pancreatic juice, consequently we find the test is positive in all cases of jaundice where there is complete or partial obstruction to the common bile duct. The test has been tried in a variety of cases, and given positive results in cirrhosis of the liver, hydatid cyst of the liver, and other diseases. The experiments carried out in vitro showed that sajodin was rendered soluble by the action of pancreatic juice or pancreatic extracts. This led me into error, as I found that it was practically impossible to obtain an active pancreatic extract without contamination with bile salts. Apart from the steapsin of the pancreas, digestion with very strong acids is the only method by which the iodine can be liberated. At first $I$ was inclined to regard this as a most valuable test, but it has failed me in so many important cases that I have now discarded it as of no value.

Diastase. The presence of starch granules in a microscopical preparation has been regarded as of diagnostic value in pancreatic insufficiency, but after an examination of many hundreds of faeces of all types, I can state without hesitation that it is an extremely rare phenomenon. The estimation of the diastase in the faeces on the same lines as that used for the urine has also been tried. In my experience it is valueless, since a normal index is so frequently found in cases of undoubted pancreatic insufficiency. Starch digestion in the alimentary canal of Europeans is remarkably complete, and I infer that there are ferments, other than diastase (amylase), in the pancreatic juice which are capable of exerting this function. During my service in India I had occasion to determine the diastase content of the faeces and found it to be normal, although microscopical examination showed abundance of starch granules in every case. The diet of such individuals is so rich in starch, that the alimentary canal is incapable of dealing with it either normally or abnormally.

The occurrence of starch in the stools is due either to undue peristalsis in 
the intestine, or to an excessive intake of starchy foods, and in my opinion has no reference to any deficiency of pancreatic juice.

(d) The oil-test brealffast. 'This test may be dismissed in a fow words. Apart from its unpleasantness to the patient the results of a trial of four cases were so indefinite that it was discarded. Trypsin is really the only ferment that can be determined with any degree of accuracy, and the activity of this ferment is influenced by so many extraneous factors, particularly the acidity of the gastric contents, as to render the results of doubtful value. In a case of carcinoma of the pylorus a diminished tryptic content of the stomach contents was found after the oil breakfast, although there was abundant evidence of regurgitation. The pancreas was found to be unaffected, and this test was the only positive indication for pancreatic insufficiency.

2. Tests depending upon other functions of the pancreas.

(a) The general characters of the urine. This subject has already been considered under the heading of clinical features of diseases of the pancreas. The records given in the summary of cases will indicate the chief constituents most frequently sought for. Attention was paid more particularly to the occurrence of pigments, such as urobilin and bile pigments, also indican, and the presence or absence of abundant crystals of calcium oxalate in the urinary deposit. Finally, the absence of ethereal sulphates in pancreatic insufficiency has received attention.

(b) The diastase content of the urine. The presence of a ferment capable of digesting starch solutions when added to urine has been known for a very long time. The subject received new interest when, in 1908, Wohlgemuth (8) published his method of estimating the amount of diastase in the urine. He showed that in pancreatie disease the diastase content of the urine was markedly increased. Since these observations were recorded a number of workers bave all obtained confirmatory evidence, but the best and most complete work is undoubtedly that of Corbett (9) in this country. He showed that there is normally a certain amount of diastase in the blood and that the same quantity is excreted by the kidneys.

If there is an increase of diastase in the blood then there is a corresponding increase in the amount of diastase in the urine provided that the kidneys are functionally unimpaired. The slightest damage to the renal epithelium leads either to a great diminution of diastase in the urine or to an increase depending upon the permeability of the kidney. Geyelin (12) came to similar conclusions as regards the influence of the kidneys in the removal of diastase from the blood. With regard to pancreatic diseases it is of interest to note that Woblgemuth and Noguchi (13) found an increase of diastase in both blood and urine where the pancreas had been injured. The results of Corbett are also striking, and there seems to be no doubt that a high diastase value of the urine is in favour of pancreatic disease, whereas a normal or low value points to a normal pancreas. Some writers, however, have suggested that these high values are only obtained in the acute stages of the disease. These observations represented 
the general trend of opinion when I first commenced my work upon the subject. The analysis of my results will be given later and compared with the other tests that have been applied. In carrying out the estimations I have followed the technique devised by Wohlgemuth in certain particulars, and the method of procedure adopted is as follows:

A full twenty-four hours' hourly collection of the urine is made into clean stoppered glass bottles, and the estimation is carried out as rapidly as possible after the full amount has been collected. The urine should be as free as possible from contamination, and where a twenty-four hourly specimen is unobtainable I generally advise a six-hourly collection, or better still a twelvehourly collection. Apart from the fact that there may be a slight rise in the diastase content of the urine preceding a meal, followed by a fall immediately afterwards lasting for from three to four hours, the rise is so slight that it is almost negligible. Except for practical purposes it does not matter whether a fresh specimen or a twenty-four hours' hourly sample of urine is used. To preserve the urine when facilities for carrying out the test are not immediately available toluol is added. This will'not affect the diastase, and, in fact, specimens may be kept for months or even years without showing any alteration in their diastase content. All other forms of preservative must be avoided, since I have found that in most cases they lead to immediate destruction of the ferment.

For the actual test only 2-3 c.c. of urine are required. The apparatus and chemical reagents required are:

(1) Ten clean dry test-tubes made of good glass, of equal bore, and of uniform thickness.

(2) Standard 10 c.c. burettes, graduated pipettes of 1 c.c. and 2 c.c. capacity.

(3) Pure distilled water.

(4) A carefully prepared solution of starch, made by dissolving $2 \mathrm{grm}$. of pure 'soluble' starch in, 100 c.c. of pure 10 per cent. sodium chloride solution. This acts as a stock solution, and the standard starch solution is made up fresh as required. 5 c.c. of this stock solution are placed in a 100 c.c. measuring flask, and diluted up to the mark with pure distilled water. This solution now contains $0.1 \mathrm{grm}$. per cent. of soluble starch in a 0.5 per cent. solution of sodium chloride, and is the solution used in all the diastase estimations recorded in this paper.

(5) A 1/50 normal solution of iodine. This has to be made up fresh as required, since it does not keep well, particularly in the summer months. The iodine solution is stored in the dark in the $1 / 10$ normal strength, and from this a fresh $1 / 50$ normal solution is made by dilating 2 c.c. of the iodine solution up to 10 c.c. with distilled water. A specially prepared dropping pipette is always used with this solution to ensure that the same number of drops of dilute iodine are added to each tube when carrying out the estimation.

(6) A reliable water bath which is maintained at a temperature of $39^{\circ} \mathrm{C}$. by means of a thermo-regulator.

(7) A wire cage to hold the test-tubes in place when immersed in the bath. 
The tests are carried out as follows: The ten test-tubes are placed in a stand and numbered in sequence. 1 c.c. of the urine to be tested is added to tube No. 1 by means of a graduated pipette, and decreasing quantities in the remaining nine tubes. We have now a series of ten test-tubes containing various decreasing quantities of urine, and these are now made up to an equal volume-1 c.c. with distilled water. It has been found that by careful manipulation, and using a standard pipette, this method of dilution gives rise to only a slight error, at least insufficient to affect the estimation.

We thus have the following series of dilutions:

$\begin{array}{rlcc}\text { (1) } & 1 & \text { c.c. of urine. } \\ (2) & 0.5 & " & " \\ (3) & 0.4 & " & " \\ (4) & 0.1 & " & " \\ (5) & 0.08 & " & " \\ (6) & 0.06 & " & " \\ (7) & 0.04 & " & " \\ (8) & 0.02 & " & " \\ (9) & 0.01 & " & " \\ (10) & 0.008 & " & "\end{array}$

All these ten tubes are now inserted into the wire cage and placed in the water bath for 15-30 minutes. This serves to bring the temperature of the mixtures up to the required level, and further activates the ferment present in the urine. The diluted starch solution is now run into each tube, 2 c.c. being used, and, after mixing, the tube is replaced in the wire cage. The wire cage is placed in the water bath and allowed to remain there for half an hour, after which time the cage is withdrawn, and placed under running water to cool the tubes to arrest any further ferment action. The ten tubes are replaced in the test-tube stand in their original order. By means of the fine-dropping pipette two drops of the freshly prepared iodine solution are added to each tube and the mixture shaken.

If the urine is normal, tubes 1, 2, and 3 will show a golden-yellow colour, indicating that the 2 c.e. of starch solution added has been completely digested by the diastase present in the urine, whilst tube 4 will have a reddish colour with no tinge of blue, tube 5 a violet tinge, and all the remaining tubes will be deep blue. In such a series tube 4 will give the reading required, since it is the tube where the starch has been digested as far as the dextrin stage. This redcoloured tube is taken as the limit tube when the above dilutions are used. After considerable experience with this method I prefer to adopt this reading rather than the somewhat indefinite mauve limit in Corbett's modification.

The calculation of the amount of diastase in the urine is now a simple matter, the result being expressed in terms of units of diastase. Thus tube 4 gives a red coloration and shows that 0.1 c.c. of the urine has digested 2 e.c. of a 0.1 per cent. solution of starch in half an hour at a temperature of $39^{\circ} \mathrm{C}$. 
Therefore 1 c.c. of urine will digest

$$
0.1: 2 \text { c.c. } \text { starch : : } 1 \text { c.c. }: X \text {. }
$$

This gives a diastase content of 20 units; in other words, 1 c.c. of the urine is capable of digesting 20 c.c. of a 0.1 per cent. solution of starch in half an hour, or, expressed symbolically,

$$
d\left(\frac{39^{\circ} \mathrm{C}}{30 \mathrm{~min}}\right)=20 \text { or } d=20 \text { units. }
$$

In dealing, with urines from cases of pancreatic disease the above method possesses many advantages, since the ten tubes give a wide range, and the differences are generally so large that minor errors of dilution, changes in volume of the urine, saline constituents, reaction, and presence of abnormal constituents have very little influence on the result. Thus we see how important it is to adopt a technique with freedom from any external sources of error, and any attempt to depart from this procedure either on the lines of simplification or amplification invariably meets with failure. After an extensive trial with this test on many hundreds of specimens of urine it has been possible to fix a standard for normal healthy individuals. The normal average value has been found to be 20 units, the maximum being 33.3 and the minimum 10 units, a sufficiently limited range from which to determine whether a given urine is normal or abnormal. The present paper deals with the use of this method for the diagnosis of diseases of the pancreas, where we expect to find an increase of diastase of such an extent that any sources of fallacy are promptly ruled out. Suffice it to say at this juncture that all possible fallacies have been considered, and since these apply more especially to the diagnosis of renal insufficiency they will not be given here. The results of these investigations have been already published in various papers by the writer dealing with acute nephritis as met with in France during the great war.

(c) The Cammidge 'pancreatic' reaction. The test devised by Cammidge over ten years ago has been the subject of considerab]e controversy, but we owe much to Cammidge for his laborious attempt to establish his test on a sound basis. Many workers have turned their attention to this test, and some still regard it as of value for diagnosis, but it has undoubtedly failed to fulfil the great expectations which were at first claimed for it. I myself carried out numerous examinations, and my colleague, Dr. Sladden, has already published his observations. In my opinion the test is of value as illustrating the phenomenon observed in my series of cases, namely, that many of these changes are of a 'fleeting character', appearing rapidly and just as quickly disappearing. The Cammidge test is time-consuming, and requires experience in carrying out the technique, and has no advantages over the estimation of the diastase in the urine. Consequently it has now been given up as a routine test in this hospital. The pathological interest of the test still remains, and it appears probable that the crystals obtained are in some way related to the presence of an abnormal amount of diastase in the urine. The new 'iodine coefficient' test has not been tried. 
(d) The Loewi adrenalin mydriasis test. This test is one of great interest, and has the advantage of being easily applied. The principles on which it is based are at present a matter of controversy. The test depends upon the fact that adrenalin instilled into the conjunctival sac produces dilatation of the pupil in certain diseases, whereas in normal persons it has no such effect. One eye is selected, care being taken to exclude any evidence of corneal injury, ulceration, or inflammation. Into this eye two drops of a $1 / 1000$ strength of adrenalin chloride are dropped, and the eye kept closed for.a few minutes. The other eye is used as a control. After twenty minutes the eyes are again examined, and if the pupil of the experimental eye shows well-marked dilatation as compared with the control eye the test is regarded as positive. The maximum dilatation is attained in half an hour, and then rapidly disappears. The dilatation is often of quite a different type to that produced by mydriatic drugs, in that the pupil assumes an oval shape, the greatest diameter being either horizontal or vertical. The first time this test was tried was in the case of bronzed diabetes described later in this paper. The result was so striking that it stimulated interest in the test, and ensured its general application.

(e) Glucose tolerance test. The urine of all the cases included in this series was examined for the presence of sugar, and the results were in many cases of great interest. One case of acute pancreatitis when admitted to the ward showed well-marked glycosuria in a catheter specimen drawn off soon after the onset of an acute attack. The next specimen of urine excreted showed no trace of sugar, and all subsequent specimens were found to be free from sugar. Glycosuria of this sudden onset was found in other cases, and might frequently have been missed altogether. The occurrence, therefore, of glycosuria, especially when so rapid and transitory, is a phenomenon of no small interest, and coincides with the excretion of large amounts of diastase in the urine. These observations have been always uppermost in my mind in attempting to explain the association of the glycosuria, the diastase in the urine, and the Loewi reaction, especially their transitory characters. The presence of glycosuria affords valuable confirmatory evidence of pancreatic insufficiency, and if not present then the glucose tolerance test is tried. This test really consists in producing a type of alimentary glycosuria, and should be carried out with all due caution. A normal healthy individual is capable of absorbing $100 \mathrm{grm}$. of glucose without passing any abnormal amount of sugar in the urine. With $200 \mathrm{grm}$. of glucose there is nearly always a temporary glycosuria. The normal tolerance is actually found to be about $150 \mathrm{grm}$. The tolerance test consists in giving a person about $150 \mathrm{grm}$. of glucose dissolved in 300 c.c. of water on an empty stomach, and in such a form that it can all be consumed within a quarter of an hour. Whilst the test is being carried out the patient is kept on a milk diet, and usually the glucose is given in the morning of the second day of the diet. The urine is collected every hour after the glucose is given, each specimen being tested for sugar.

In cases where there is reason to suspect pancreatic insufficiency, a dose of 
only $25 \mathrm{grm}$. is given for the first test, as there is the danger of putting too great a strain on the patient's tolerance with larger doses, which may lead to a persistent glycosuria. We can then test the tolerance to larger doses by stages if no glycosuria occurs. The occurrence of glycosuria after a dose of 25,50 , or $100 \mathrm{grm}$. of glucose does not necessarily imply that the pancreas is at fault, since disturbance of liver function and other diseases may yield similar evidence of lowered glucose tolerance. As a test, therefore, it simply serves as a useful guide, and the results should always be interpreted with dne cantion. Estimations of the blood-sugar content should also be made both before and at intervals after the administration of glucose by the mouth.

\section{The Value of the Methods used in certain selected Cases.}

To illustrate the value of the functional tests described in the preceding paragraph a brief note on a few selected cases is appended. They serve to show the extent of the inquiry and to supplement the records given in the tables.

Case I. The first case has already been fully described in this Journal, in a paper entitled 'A Contribution to the Study of Bronzed Diabetes.', Jan., 1914, vii.

Case I. P. B., aged 44 , a chemist and druggist by trade, was admitted under the care of Dr. A. E. Garrod on April 17, 1912, suffering from diabetes mellitus. On admission he was diagnosed as a case of bronzed diabetes, and a number of chemical tests were carried out during the course of the illness.

Summing up the results obtained the following tests suggested pancreatic insufficiency :

(1) Diastase in the urine.

(2) The occurrence of creatorrhoea (Schmidt's test).

(3) Loewi's adrenalin mydriasis test.

(4) Sahli's stearin capsule test.

(5) Lowered glucose tolerance and glycosuria.

The tests which did not support such a conclusion were :

(1) The absence of steatorrhoea.

(2) The normal tryptic and diastatic content of the faees.

(3) The negative Cammidge 'pancreatic' reaction.

(4) The absence of oxaluria and indicanuria.

The pancreas at autopsy was found to be soft, misshapen by firm adhesions, and on section appeared of a deep brown colour. Histological examination showed well-marked fibrotic changes with abundant deposition of an iron-containing pigment.

Case II. W. D., aged 59, a carman by trade, was admitted to St. Bartholomew's Hospital on March 31, 1919, under the care of Sir Archibald Garrod, suffering from pain in the stomach and jaundice. His illness began December, 1918, with a feeling of weariness and fatigue. Two months later he was noticed to be yellow, but he had observed that his urine was dark in colour shortly before 
this. At the same time he felt a dull aching pain across the upper part of the abdomen, especially after meals, which gradually became worse. There was no vomiting or constipation. The patient felt sure he had lost weight during the early months of 1919 .

He had never suffered from jaundice before, but admitted he had been a very heavy spirit drinker before the advent of the war restrictions. On admission the patient appeared deeply jaundiced, with a soft, dry, and slightly irritable skin; soft enlarged glands were observed in the left supraclavicular fossa, but otherwise nothing of note was discovered in the chest. Examination of the abdomen revealed considerable enlargement of the liver, but the gall-bladder could not be felt. There was no ascites.

Rectal examination did not indicate any abnormality or growth in this region. The urine was of a dark brownish colour, acid in reaction, contained bile pigments, and gave a doubtful reduction with Fehling's test for sugar. The stools were clay coloured.

A diagnosis of carcinoma of the liver was made. About one week after admission sugar was definitely found in the urine, and the pancreas was at once placed under suspicion.

From this time onwards a complete investigation was made with a view to onfirming the presence of pancreatic involvement.

The urine contained sugar to the extent of 1.2 to 1.4 per cent., and maintained this amount during the whole course of the illness. Daily estimations were made on the twenty-four hourly samples, the total sugar ranging from a mere trace to $36 \mathrm{grm}$. There was no indicanuria, but large quantities of indoxyl glycuronates were excreted daily and frequently separated out as a blue sediment. This accorded with the absence of ethereal sulphates in the urine, a fact so frequently observed in cases of pancreatic insufficiency, and forms the subject of a separate inquiry by the writer. The presence of creatine in the urine was established, and was thought to indicate carcinoma of the liver. The daily variations in excretion of this substance were recorded, as also the effects of administration of creatine and creatinine by the mouth. A large number of observations have been made in this hospital, and these will form the subject of a separate communication. Suffice it to say at the moment that the presence of creatine in the urine is of no diagnostic value, and depends upon factors other than disease of the liver, which though fundamental are yet obscure.

The diastatic activity of the urine was estimated at intervals with the following results:

$\begin{array}{rcccc}\text { Date. } & \begin{array}{c}\text { Volume of } \\ \text { Urine in c.c. }\end{array} & \begin{array}{c}\text { Sugar. } \\ \text { Total in Grm. }\end{array} & \begin{array}{c}\text { Diastase in } \\ \text { Urine. Units. }\end{array} & \begin{array}{c}\text { Normal Diastase. } \\ \text { Average Units. }\end{array} \\ \text { April 15 } & 1,000 & 12 & 125 & 16 \\ \text { May } 11 & 1,780 & 19 \cdot 58 & 62.5 & 16 \\ \text { "18 } & 935 & 0.935 & 25 & 16 \\ & 2,180 & 15 \cdot 26 & 32 & 16\end{array}$

The diastase content of the urine was abnormally high, but subsequently fell, although not to the normal level. This has been my experience of several similar cases, indicating that as the disease progresses the tendency is for the diastase to fall to normal or even below a normal value. Consequently in a case of long standing, or one where rapid destruction of pancreatic tissue has taken place, it may be difficult to draw any conclusion other than that the functions are seriously deranged. It bears no relation to the volume of the urine, or to the amount of sugar excreted.

Loewi adrenalin mydriasis test. This test was first tried on the left eye and gave a negative result. Subsequently it was found that the left pupil was not round, as in the right oye, but fixed by synechiae. When the test was tried on the right eye very definite dilatation was observed, and proved positive with 
one exception. The test was applied on two consecutive days, and failed on the second day. After six days' interval the test was again positive. These observations are of great interest for two reasons: first, the importance of examining both eyes before carrying out the test, and secondly, the recognition that there is a definite fatigue period following the dilatation, during which period adrenalin ceases to have any effect. The clay-coloured stools were tested for urobilin and found to be negative, thus establishing the fact that no bile pigments were entering the intestine or, in other words, there was complete obstruction to the common bile duct.

The 'sajodin' test next occupied attention, the sajodin being given after breakfast in one single dose of $7 \frac{1}{2}$ grains. No iodides could be detected in the urine even for forty-eight hours after administration, whereas two normal healthy individuals excreted iodides within five to six hours after swallowing a similar dose. In view of the fact that no bile salts were entering the intestines this result is not surprising, and seriously militates against the practical utility of such a test.

Occult blood, the presence of which was detected by the benzidine test, was present on all occasions, care being taken to exclude any extraneous sources of blood or blood-products in the food. This finding was in my opinion very significant, since it established the fact that we were dealing with a malignant growth of the pancreas rather than a simple pancreatitis.

The faeces were examined on three occasions, and to emphasize the value of the results obtained I give them in tabular form:

\begin{tabular}{|c|c|c|c|c|}
\hline Appearance. & $\begin{array}{l}\text { April 17, } \\
\text { Greyish White, } \\
\text { Pasty. }\end{array}$ & $\begin{array}{l}\text { April 26, } \\
\text { White, Pasty } \\
\text { Stool. }\end{array}$ & $\begin{array}{c}\text { April } 30, \\
\text { Clay-coloured, } \\
\text { Oily. }\end{array}$ & $\begin{array}{c}\text { Normal Values } \\
\text { Brown. }\end{array}$ \\
\hline $\begin{array}{l}\text { Reaction } \\
\text { Urobilin } \\
\text { Blood } \\
\text { Water } \\
\text { Total fat } \\
\text { Neatral fat } \\
\text { Fatty acids } \\
\text { Soaps } \\
\text { Ash }\end{array}$ & 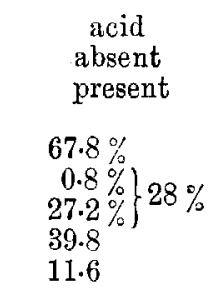 & $\begin{array}{c}\text { acid } \\
\text { absent } \\
\text { present } \\
60.2 \\
71.0 \\
56.6 \\
14.4 \\
10.0\end{array}$ & $\begin{array}{c}\text { acid } \\
\text { absent } \\
\text { present } \\
65 \cdot 2 \\
70 \cdot 0 \\
59 \cdot 0 \\
11 \cdot 0 \\
8.0\end{array}$ & 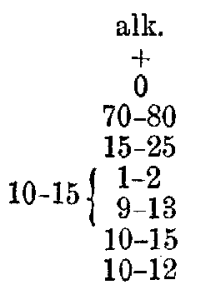 \\
\hline \multicolumn{5}{|l|}{ Microscopical: } \\
\hline $\begin{array}{l}\text { Muscle fibres } \\
\text { Fat globules } \\
\text { Fatty acid crystals } \\
\text { Soaps } \\
\text { Vegetable débris } \\
\text { Crystals } \\
\text { Diet }\end{array}$ & $\begin{array}{c}\text { absent } \\
\text { a few seen } \\
++ \\
0 \\
++ \\
0 \\
\text { no meat }\end{array}$ & $\begin{array}{c}\text { absent } \\
+ \\
++ \\
0 \\
++ \\
0 \\
\text { no meat }\end{array}$ & $\begin{array}{c}+++(\text { nuclei }) \\
++ \\
+ \\
0 \\
+ \\
0 \\
\text { minced beef } \\
\text { added }\end{array}$ & $\begin{array}{c}+ \\
\text { traces } \\
0 \\
\text { a few } \\
+ \\
+ \\
\text { mixed diet }\end{array}$ \\
\hline
\end{tabular}

The results clearly justify the labour expended, since from the first analysis we should conclude that the changes present were largely biliary in origin. By taking into account the total fat values, however, a definite deduction can be drawn. In all cases of obstruction of the common bile duct without involvement of the pancreas, we never find the total fat value above 50 per cent., whereas in cases of pancreatic insufficiency figures much higher than this are the rule. The faeces in this case give evidence therefore of steatorrhoea, and the values for the different forms of fat show very clearly the gradual loss of fat-splitting powers as the disease progressed. In the last specimen examined there was a much 
greater proportion of unsplit fat present than in the two previous specimens and a corresponding diminution in the amount of soaps.

Creatorrhoed. The simpler and much more efficient method of carrying out this test was adopted in preference to the original Schmidt test. The patient was given a diet containing no meat for several days, and one day at mid-day a quantity of under-cooked minced beef was administered. The stools were examined the following day, and showed abundant muscle-fibres with the characteristic striations, and even nuclei. This simple test can always be carried out and really embodies that of Schmidt and Kashiwado's modification of the same. The faeces examined on April 30, recorded in the table above, therefore demonstrate that there was well-marked creatorrboea in this case. The patient suffered from severe abdominal pain and wasting, and died on June 11, 1919.

At the autopsy the pancreas was found to bo hard and nodular, and almost entirely replaced by a malignant growth. The common bile duct was much distended and thin walled. The gall-bladder was much enlarged and bound down by adhesions to the liver, and this accounted for the fact that it was not palpable during life. The liver was much enlarged, but no obvious growth could be detected. On the upper surface of the left lobe several distended bile ducts could be seen. The whole of the liver and adjacent viscera, including the stomach, duodenum, and pancreas, were preserved entire, and will be dissected and described later. This case was interesting from many points of view, since all the tests applied pointed to disease of the pancreas, and the clinical diagnosis was as certain as it was possible to be in such a case.

Summing up the evidence in favour of pancreatic disease we have:

(1) The high diastase content of the urine.

(2) The occurrence of persistent glycosuria.

(3) The positive Loewi test.

(4) Well-marked and increasing steatorrhoea.

(5) Creatorrhoea.

(6) A positive sajodin test.

(7) The occurrence of occult blood in the stools.

(8). The absence of ethereal sulphates and indican, and their replacement by indoxyl glycuronates.

(9) The absence of urobilin in the faeces.

This case, therefore, illustrates the value of the application of particular laboratory methods, which, in the experience of the writer, have proved of the greatest value in assisting or confirming the diagnosis of pancreatic disease.

Case III. M. B., aged 50, a gas-worker by trade, was admitted to St. Bartholomew's Hospital on February 14, 1919, under the care of Dr. Langdon Brown, suffering from jaundice and pain in the stomach. Two months previously he had attacks of vomiting in the morning, and two weeks later abdominal pain, which was worse after food. He became yellow one week later. He had had no previous illnesses, but had been a heavy drinker, particularly of beer. His father died of 'cancer'. 
On admission he had marked jaundice and pruritus, with a slow pulse and a soft systolic murmur at the apex of the heart. The liver was not uniformly enlarged, but a smooth elastic globular swelling was felt in the position of the gall-bladder. The urine contained bile pigments, but no bile salts, and gave a doubtful reduction with Fehling's test for sugar. The faeces showed a slight reaction for urobilin, and two tests for occult blood proved negative.

On February 21 the urine was systematically examined, but no sugar could be detected, the doubtful reduction of Fehling's test being probably due to the excess of bile pigment present.

The faeces examined the same day showed no trace of urobilin, muscle fibres were absent, and there was no excess of unsplit fat. Occult blood was again absent.

Faeces. The following results were obtained :

Appearance
Odour
Reaction
Urobilin
Mucus
Blood
Microscopically:

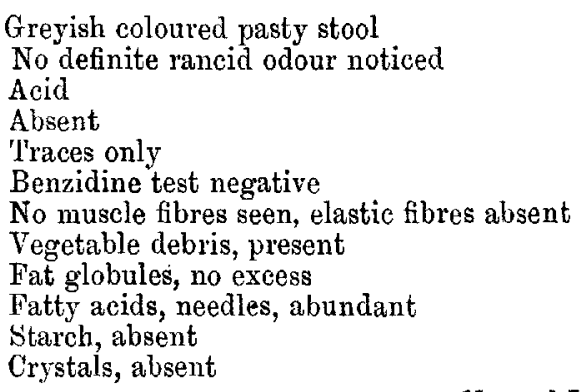

Total fat

$=63.36$ per cent, of dried faeces

$\begin{array}{llll}\text { Combined fatty acids } & =52 \cdot 7 \quad, \quad, \quad, \quad, & , & ,\end{array}$

Organic matter $\quad=89.4 \quad, \quad, ", "$,

Inorganic ash

Normal Values.
$15-25$
$10-15$
$10-15$
$85-89$
$10-12$

The results showed that the total fat was much higher than could be accounted for by simple obstruction to the common bile duct; in other words, there was steatorrhaea, and thus evidence of pancreatic insufficiency. The patient was on a meat-free diet, and this accounted for the absence of muscle fibres in the stools.

The diagnosis made was complete obstruction to the common bile duct, possibly due to a malignant growth. The diastase content of the urine amounted to 128 units, and the pancreas was, therefore, considered to be implicated.

As a result he was transferred to a surgical ward, and an exploratory operation was performed by Mr. Rawling on March 6. The common bile duct was found to be completely obstructed, but the nature of the obstruction could not be determined. The pancreas appeared to be enlarged and hard, and this change was considered to be inflammatory in origin. Drainage of the gallbladder was carried out and the patient made an uninterrupted recovery. There was, however, a small permanent biliary fistula remaining, from which pure bile flowed, and the patient left the hospital provided with an instrument for the collection of the bile.

After the operation the following tests were carried out:

The diastase in the urine on May 20, over two months after the operation, had fallen to the normal value of 16 units, indicating that the pancreas was recovering its function. 
Loewi's adrenalin mydriasis test was markedly positive on May 17, but proved negative one week afterwards.

The 'sajodin' test was negative, no iodides being found in the urine after the ingestion of $7 \frac{1}{2}$ grains of sajodin given in one dose.

Again, we have the test applied where there was evidence that no bile salts were entering the intestine, and therefore no real indication could be obtained as to whether the pancreatic secretion was also occluded from the intestine.

Occult blood. On a meat-free diet several separate tests were performed, and in every case a positive benzidine test occurred. This result pointed to some bleeding ulcerated surface in the gastro-intestinal tract, possibly from the obstructed common bile duct.

Creatorrhoea. On May 18 a meal of under-done minced beef was administered, and the faeces examined the following day. There was abundance of large wellstriated muscle fibres, which when stained showed nuclei.

The diagnosis is still in doubt, but from the improvement in the patient's condition, it does not appear probable that the obstruction was due to a growth in the common bile duct. That there was chronic pancreatitis is beyond doubt, but this was probably secondary to what $I$ believe to be an old ulcer situated in the duodenum close to the opening of the common bile duct and pancreatic duct.

The evidence for pancreatic insufficiency in this case is therefore provided by the following tests :

(1) High urinary diastase content early in the disease, later falling to normal.

(2) The presence of a high total fat content-more than 50 per cent.

(3) Creatorrhoea.

(4) Positive Loewi reaction.

(5) A positive sajodin test, absence of urobilin in the faeces.

The three selected cases above described represent the type of work involved, and express very clearly the main issue. Their number could be multiplied, but it is considered proper to the occasion to submit the remaining cases in tabular form. In the summary of cases printed at the end of the paper all the cases are grouped under the commoner classes of disease to which the pancreas is prone-acute pancreatitis, chronic pancreatitis, and malignant disease of the pancreas respectively. A group of cases of liver disease is included, as also some forms of intestinal diseases, and lastly cases of diabetes mellitus. In many of these patients complete analyses of the urine and faeces have been made, but these results have been excluded on account of the necessity of conserving space; they will be briefly discussed in the text.

\section{Discussion of Results.}

An excellent summary of our knowledge of the methods of diagnosis of pancreatic disease up to the year 1914 has been given by my colleague Dr. Sladden (15), who worked in my laboratory during 1913. This paper embodied in a critical review the present state of our knowledge with regard to 
several of the functional tests mentioned in this paper. Under the circumstances it is unnecessary for me to dwell upon the conclusions of other writers, and the reader is referred to this paper for the information he may require. My present object is to detail my own personal experience of the various tests, gained as the result of several years' work upon the subject. The publication of these results was delayed by the war, although the greater part of the work was done in the pre-war period. In some ways this delay has been fortunate, since $I$ have been able to apply my observations to two interesting cases since my return, and these are incorporated in the text in a description of selected cases. The clinical classification of diseases of the pancreas has been adopted, and it will be convenient to discuss the results under three headings: acute pancreatitis, chronic pancreatitis, and malignant disease of the pancreas.

Acute pancreatitis is a disease in which early diagnosis is of the greatest importance, consequently it is not possible to apply any tests which involve lengthy laboratory methods. In such cases an examination of the urine, tests for occult blood in the stools, microscopical examination of the faeces, and the Loewi test, are the only tests which can be carried out in the limited time allowed. Fortunately these tests have proved quite sufficient if one may judge from the tabulated series of cases below (No. I). By far the most important is the diastase content of the urine, and a fresh specimen of urine can generally be obtained, and the result completed within an hour. At the same time it is quite easy to do a Loewi test on the eye, and also to obtain a sample of the rectal contents by means of a plain water enema. The diastase content is almost invariably high, especially in the acute stages of the disease. When this stage has passed off the diastase content of the urine falls even to a normal value. The figures in the summary (No. I) illustrate this change. The fall may occur in a few hours, as for example an original diastase content of 200 units became 100 units the following day. The same 'fleeting' character is often found in the case of sugar in the urine. The most striking example was one case of acute pancreatitis where sugar was found in a catheter specimen of urine drawn off for diagnostic purposes, and subsequently the urine contained no sugar. The glycosuria, if present, may therefore last for only a few hours, a few days, or may persist for weeks, but sugar is not by any means constantly present in acute pancreatitis. The observations on the Loewi test are also of interest, since the positive results were obtained in those cases where there was a high diastase content of the urine, and also glycosuria. What a remarkable association! one which gives much food for thought and speculation. This association, which I describe as the 'tripod' tests, has never been deseribed before, and from my series of cases I am inclined to regard it as of great importance. Apart from their value for diagnostic purposes these tests point the way to a possible solution of the problem of the exact function of the pancreas in controlling carbohydrate metabolism. The chief characteristic is their early manifestation, pointing to a sudden disturbance of some chemical mechanism. The close relation between the suprarenals and the pancreas, and the possibility of the 
Loewi test being associated with the sympathetic nervous system, particularly the chromaffine portion of that system, has led me to devote my labours to this phase of the problem. A new method of estimating adrenalin and lipoids in the blood is at present under investigation. No quantitative proof has so far been forthcoming of the increased adrenalin content of the blood in pancreatic disease, although the observations of Pemberton and Sweet (16) on the influence of the adrenals over the pancreas are sufficiently striking to warrant such an investigation. These writers showed that intravenous injections of adrenalin, and of pituitary extract, inhibit the flow of pancreatic juice even after the blood pressure has returned to normal. The remarkable histological changes produced in the liver cells, particularly those lining the bile ducts, by repeated injections of adrenalin are well known to those observers who have worked on the causation of shock, and I have no doubt similar changes could be found in the pancreas, especially in the cells lining the ducts. The pancreas being thrown out of action is unable to balance the adrenalin secreted by the adrenals, and the blood receives an excessive amount of adrenalin-with the result that glycosuria occurs, and with it a rise in the diastase contents of the blood and urine, and a positive Loewi mydriasis test. Secretion of pancreatic juice is arrested, not through any deficiency of 'secretin', but through the excess of adrenalin in the blood. The obstruction to the flow of pancreatic juice leads to autolysis, with the resulting haemorrhage and fat necrosis. To complete the whole picture we want to know the adrenalin content of the blood, and this is my present objective. The examination of the faeces usually yields no conclusive evidence of pancreatic insufficiency in cases of acute pancreatitis, although the almost constant occurrence of occult blood is worthy of record. The Cammidge test was negative in three cases, but this has been the experience of a number of other workers, including Sladden (14). To sum up the results on acute pancreatitis, the association of glycosuria, an increased diastase in the urine far exceeding normal values, and a positive Loewi test afford very strong presumptive evidence of pancreatic involvement.

Passing now to the cases of inflammation of the pancreas of a more chronic type, one may refer to the record of twenty-eight cases reccorded in the summary (No. II). Perhaps the most striking case was that of bronzed diabetes, where the pancreas was found to be completely cirrhosed at the autopsy. The following tests gave positive evidence of pancreatic insufficiency: Schmidt's test, Sahli's test, glycosuria, Loewi's adrenalin mydriasis test, and inereased diastase in the urine. The Cammidge test, trypsin content of the faeces, diastase content of the faeces, and fat content of the stools wore all negative. This case illustrates very well the true value of the tests as applied to any individual case. Reviewing all the results we find that there is no one test which is of absolute value in diagnosis. Creatorrhoea and steatorrhoea are of fairly common occurrence, but by no means constantly present, and the same applies to the Schmidt test and Kashiwado's modification when these were applied. A perusal of the summary will also show how frequently the Cammidge 'pancreatic' reaction was 
negative, only one positive reaction being recorded in this series. The general urinary changes were not striking, and it cannot be said that urobilinuria, indicanuria, or oxaluria are in any way characteristic of pancreatic disease. The frequent association of a high diastase content of the urine, a positive Loewi mydriasis test, and the occurrence of glycosuria or a lowered glucose tolerance is again evident. The diastase values are not generally so high as those of acute pancreatitis, but one case stands apart-R. G., a clinically typical case of chronic pancreatitis. The diastase in the urine was 1,000 units, but after treatment fell to 50 units, and the patient eventually recovered. Another case showed 100 units, then 50 units, and after an interval of one year only 5 units. This patient died whilst I was abroad, but there is reason to suppose that his pancreas gradually lost its function, and eventually failed altogether. Associated with this high diastase was well-marked glycosuria and a positive Loewi. There were also creatorrhoea and steatorrhoea, as evidenced by repeated analysis of the stools. Another case, R. W., who had a permanent biliary fistula with chronic pancreatitis following upon an attack of acute cholecystitis, gave a diastase value of 100 units on three separate occasions, whilst the Loewi test was always negative, and therewas no glycosuria. There were, however, creatorrhoea and steatorrhoea. The case designated No. 3 in the group of selected cases described (Summary I) is of interest as illustrating the triple association, and also the temporary character of the tests. The diastase rapidly fell from 128 units to the normal value of 16 units, the glycosuria was also transient in character, and the Loewi test was changed from a positive to a negative mydriasis within an interval of one week. Here, again, there were creatorrhoea and steatorrhoea, but the latter was more characteristic of biliary obstruction rather than of actual pancreatic insufficiency. The 'sojodin' test was positive in so far as it represented both biliary and pancreatic insufficiency. The summary also shows several other cases of the same type sufficient to warrant a definite conclusion. It may be laid down that if these tbree tests are positive the pancreas is under grave suspicion, and the diagnosis is confirmed by the application of other tests of functional activity, more particularly the presence of creatorrhoea and steatorrhoea in the faeces. A most important point which is strongly emphasized in this work is early diagnosis, since the three cardinal tests may all be negative later, and the diagnosis left in doubt.

The diagnosis of pancreatic disease by means of these tests has frequently been the subject of controversy, and failures to obtain positive results have been rather the rule than the exception. I maintain that these observers have failed to realize their 'flecting' nature, and have carried out the tests on cases where the disease has so far progressed as to leave no doubt as to the diagnosis, without the necessity of applying functional tests. A glance through the records of my series of cases will clearly demonstrate this, and it is with pleasure that corroboration of this work is to be found in a paper by Dr. Laurence Humphrey (17) of Cambridge, who reported two cases where the urinary diastase and the Loewi adrenalin mydriasis test were positive. 
The same conclusions can be drawn from the series of cases of malignant disease of the pancreas (No. III). Case No. 2 becomes almost a complete experimental observation. The triple association is again to the fore. The glycosuria suddenly appeared one week after admission, and showed wide variations from a mere trace up to $30 \mathrm{grm}$. per diem. During the progress of the disease the diastase fell to a low level, and had the estimation been made in the later stages it would have been considered a negative result, and in consequence valueless from a diagnostic point of view. The results of the tests therefore were all in favour of pancreatic insufficiency, and the diagnosis made as certain as any clinical diagnosis could be, the ultimate proof being obtained at the autopsy. In passing, attention is called to the almost constant occurrence of occult blood in the stools, a phenomenon of some importance in differential diagnosis and treatment, since in the majority of cases of chronic pancreatitis no such evidence of haemorrhage in the intestinal tract is found.

The tests bave been applied to a large number of cases of diseases of the liver, and particularly those where the pancreas has been under suspicion. The first case in the summary (No. IV) might almost be regarded as one of subacute pancreatitis, although no definite evidence was available at the time. Unfortunately the diastase estimation was not perfected at the time this patient was in hospital. The transitory Loewi test, and the temporary glycosuria together with steatorrhoea, are significant features in view of the results described above.

The other cases are of interest in demonstrating the low values for diastase compared with those in cases of pancreatic disease. Also the occasional occurrence of a positive Loewi test in three cases where the pancreas proved to be normal at the operation or autopsy. The results clearly show that it is not safe to dogmatize and to draw conclusions as to whether the pancreas is healthy or not on any one test. Taken by itself the Loewi test is almost valueless, since it is apt to lead to an entirely wrong conclusion. This in itself is to be regretted, since it is such a simple bedside test, and causes little inconvenience to the patient.

In the group classified under other diseases the type of case is of sufficient clinical interest to warrant a full discussion, but time and space will not admit of this in the present paper.

In the remarkable collection of cases of coeliac disease it will be noted that the diastase is always on the high side of normality, and there is frequently an associated steatorrhoea. Complete and definite evidence of any pancreatic insufficiency is, however, wanting, and with the present state of our knowledge of this disease such a conclusion is unjustifiable. No apology is made for including two cases of congenital steatorrhoea under this group. The valuable contribution of Garrod and Hurtley (18) on the subject is of great interest. Their case I was able to study subsequent to their publication, and could find no evidence of pancreatic insufficiency apart from the steatorrhoea. These cases, undoubtedly, belong to the class of inborn errors of metabolism, and the error is due to a congenital absence of steapsin or its precursor in the pancreatic juice. 
Perhaps the most interesting group of cases are those of glycosuria, both temporary and permanent. The attempt to lay the blame upon the pancreas was the real and primary reason for this research. It has failed to incriminate the pancreas, not because that organ is free from disease, but because our tests for its lesions are inadequate. All the tests have so far proved negative, and in this connexion it is of interest to recall that Loewi introduced his test as one for diabetes mellitus. In my series the Loewi test has been consistently negative. The diastase content of the urine, contrary to all expectations, has been normal in every case. Further, all the tests for efficiency of the external secretion of the pancreas have yielded negative results in that no disturbance of functional activity has been found. Can it be that here again the tests are 'fleeting' in character and are missed because we do not see cases until the glycosuria or diabetes mellitus has become well established? A case of intermittent glycosuria, which I described in the St. Bartholomew's Hospital Reports with my colleague Dr. Roper (19), was thought to be an early case of diabetes mellitus. All the available tests for pancreatic insufficiency were applied, but with negative results. The conviction that the pancreas is the primary seat of disease in all cases of glycosuria and diabetes mellitus is gradually gaining ground, especially in the light of the recent work of Allen in America on diabetes mellitus. The results in my series serve to show that we are not yet on the right path to the solution of this problem, and until we know more of the part played by the pancreas in governing carbohydrate metabolism, and the interrelation of the ductless glands, our progress is necessarily slow.

In conclusion I would refer to the last seven cases recorded in the summary to illustrate the fallacies associated with certain tests, particularly the Loewi test. This test has been found positive in a variety of conditions where the pancreas is not obviously diseased. The outcome of the test therefore is that whilst advocating its general use it should be received with a healthy scepticism and freedom from bias. To discard it as a failure is unwarranted, and contrary to all the principles of clinical medicine, which advances when it takes cognizance of the collected data and carefully weighs all the evidence in the balance. The observations recorded in this paper are therefore sufficiently numerous and varied to show that no one test of pancreatic insufficiency is of value in the diagnosis of disease of that organ. Amongst all the tests so far devised I place three together as of the greatest value collectively. These are(1) The diastase content of the urine and blood. (2) The Loewi adrenalin mydriasis test. (3) The occurrence of glycosuria, or a lowered glucose tolerance.

These three tests, it must be remembered, give results which are transitory in character, so that it does not follow that if all are negative there is no disease of the pancreas. If all three are positive then there is strong evidence sufficient to put the pancreas under suspicion. The diagnosis is confirmed if in association with these three tests we find creatorrhoea and steatorrboea.

The ideal course is, undoubtedly, a complete survey of all the tests in every case, but one that is very rarely attained in this materialistic world, where the 
old saying 'time is money' has received added force and meaning since the advent of the war.

\section{Conclusions.}

(1) To prove the individual and collective value of certain functional tests for the diagnosis of diseases of the pancreas has been the main object of this work.

(2) There is no one test so far devised which can be said to be pathognomonic of pancreatic insufficiency.

(3) The association of positive results in three tests, the increased diastase content of the urine, the Loewi adrenalin mydriasis test, and the presence of glycosuria, affords strong evidence that the pancreas is at fault.

(4) If there is in addition creatorrboea and steatorrhoea, the suspicion of pancreatic insufficiency is confirmed.

(5) The transitory character of the phenomena which give positive results of diagnostic value must never be lost sight of when summarizing the evidence obtained from laboratory methods, and applying them to confirm or disprove the clinical diagnosis.

(6) The results of an investigation of cases of diabetes mellitus have been negative, in that the tests bave not supplied any evidence of gross disturbance of pancreatic function in this disease.

(7) A review of the recorded cases reveals the fact that certain tests in their present form are of no value in the diagnosis of pancreatic disease, and should therefore be discarded. This applies more particularly to the methods of estimation of trypsin and diastase in the oil-test meal and faeces, the Sahli test, Kashiwado's modification of Schmidt's test, and the Cammidge 'pancreatic' reaction. To this list may be added the 'sajodin' test of Winternitz in view of its doubtful utility.

The expenses connected with this research were in part defrayed by a grant from the Government Grant Committee of the Royal Society, and the writer wishes to express his gratitude to the members of this Committee for their help. $\mathrm{He}$ would also express his indebtedness to the physicians and surgeons of St. Bartholomew's Hospital, London, without whose help and co-operation this work would have been rendered impossible.

\section{REFERENCES.}

1. Garrod, B. M. J, 1920, April 3, 'The Schorstein Lecture'.

1*. Von Mering and Minkowski, Arch. f. exper. Path. u. Pharm., 1889, xxvi. 371.

2. Bayliss and Starling, Journ. Phys., 1902, xxviii. 325.

3. Kashiwado, Deutsch. Arch: f. Klin. Med., 1911, civ. 584.

4. Sahli, Deutsch. med. Woch., 1897, xxiii. 7.

5. Muller and Schlecht, Med. Klinik, 1909, v. 573 and 618; also Munch. med. Woch., $1908,1 v .225$. 
6. Gross, Awch.f. exper. Path. u. Pharm., 1907, lviii. 157; also Deutsch. med. Woch., 1909, xxxv. 1706.

7. Stegmann. (Winternitz Diagnostic Test.) Inang. Diss. Greiswald, 1911.

8. Wohlgemuth, Bioch. Zeit., 1909, xxi. 432; Berl.klin. Woch., 1910, xlvii. 92.

9. Corbett, Quart. Joum. Med., 1912-13, vi. 351.

10. Cammidge, Medico-Chir. Trans., 1906, lxxxix. 239.

11. Loewi, Arch. f. exper: Path. u. Pharm., 1908, lix. 83.

12. Geyelin, Arch. of Int. Med., 1914, xiii. 96.

13. Wohlgemuth and Noguchi, Berl. klin. Woch., 1912, xlix. 1069.

14. Sladden, St. Bartholomew's Hospital Reports, 1914, xlix. 19.

15. Sladden, Quart. Journ. Med., 1914, vii. 455.

16. Pemberton and Sweet, Arch. of Int. Med., 1918, x. 169.

17. Laurence Humphrey, B.M.J., 1914, 1229.

18. Garrod and Hurtley, Quart. Journ. Med., 1612-13, vi. 242.

19. Wallis and Roper, St. Bartholomew's Hospital Reports, 1912, xlviii. 19.

\section{Summary of Cases.}

\section{Acute Pancreatitis.}

Case 1. H. B., male, aged 38. Diagnosis: Acute pancreatitis, fat necrosis, and acute nephritis. Diastase in urine: 200 units. Loewi test: positive. Urine: Glycosuria (increasing). Urobilin, indican, and calcium oxalate crystals absent. Cammidge test negative. Remarks: Glycosuria. 3-4 weeks before acute onset-patient died in coma.

Case 2. B. C., female, aged 57. Diagnosis: Acute haemorrhagic pancreatitis; fat necrosis. Operation : drainage of head of pancreas. Diastase in urine: Before operation, 200 units : after operation, 100 units. 2 years later, 128 units. Loewi test: Negative on three occasions. Urine: Sugar absent, acetoacetic acid present. Sugar present two years later. Faeces : Nil abnormal. Occult blood present. Remarks: Acute abdominal pain and vomiting. Patient recovered after operation. Exacerbation of acute pancreatitis two years later-sugar detected in the urine. Exploratory laparotomy. Patient still alive.

Case 3. S. B., male, aged 50. Diagnosis: Acute pancreatitis; duodenal ulcer. Operation. Diastase in urine : 128 units. Loewi test : pegative. Urine: No sugar. Faeces: Occult blood present. Remarks: Abdominal pain. Patient left hospital improved.

Case 4. M. H. R., female, aged 50. Diagnosis: Acute panereatitis; cirrhosis of liver. Diastase in urine: 222.2 units. Loewi test: positive. Urine: Urobilin present. Sugar absent. Faeces: Creatorrhoea; steatorrhoea. Occult blood present. Remarks: Abdominal pain, and vomiting followed by jaundice. Acute attack of pain and vomiting. Recorery.

Case 5. W. G., male, aged 50. Diagnosis : Acute haemorrhagic pancreatitis with fat necrosis. Operation and autopsy. Diastase in urine: 200 units. Loewi test: positive. Urine: Sugar detected on one occasion only. Cammidge test negative. Faeces: Steatorrhoea, but no creatorrhoea. Occult blood present. Remarks: Operation diagnosis confirmed at autopsy.

Case 6. F. M., male, aged 55. Diagnosis: Acute pancreatitis. Operation and autopsy. Diastase in urine : 200 units. Loewi test: positive. Urine: Sugar, urobilin, and albumin present. Cammidge test negative. Faeces: No steatorrhoea. Occult blood present. Fluid from drainage tube-no ferments detected. Remarks : At operation pancreas hard and enlarged, with extensive haemorrhages into it. Empyema of right side. At autopsy the pancreas was found to be gangrenous.

Case 7. J. W., male, aged 62. Diagnosis : Acute haemorrhagic pancreatitis ; fat necrosis. Operation and autopsy. Loewi test: positive. Urine: Sugar present. Remarks : Operation: drainage of head of pancreas. Antopsy. The head and neck of the pancreas were haemorrhagic 
and friable, with fat necrosis. Both the costal and diaphragmatic surfaces of the pleura also showed fat necrosis. There were two gall-stones present in the gall-bladder. Trichina spiralis was found in the skeletal muscles.

Case 8. A. P., female, aged 44. Diagnosis: Acute pancreatitis. Diastase in urine: 200 units (before operation), 100 units, then $\mathbf{5 0}$ units after operation. Loewi test: twice negative. Urine: Glycosuria. Faeces: No steatorrhoea. Urobilin present. Occult blood absent. Remarks: Operation-acute pancreatitis with fat necrosis, drainage of head of pancreas and gall-bladder. Recovery.

\section{Chronic Pancreatitis.}

Case 1. J. H., male, aged 43. Diagnosis: Obstructive jaundice; chronic pancreatitis. Diastase in urine: 100 units. Loewi test: negative. Urine: No sugar present. Bile pigments and albumin present. Faeces: Clay-coloured. Remarks: Patient recovered.

Case 2. G. M., male. Diagnosis: Chronic pancreatitis. Diastase in urine: 100 units, then 50 , and 5 units one year later. Loewi test : positive. Urine: Persistent gly cosuria and indicanuria. Stools : Clay-coloured; well-marked steatorrhoea and creatorrhoea. Occult blood absent. Remarks : Chronic pancreatitis of long standing with much wasting. Died.

Case 3. R. W., male, aged 47. Diagnosis: Acute cholecystitis, chronic pancreatitis. Operation. Diastase in urine: 100 units on three occasions. Loewi test: negative on three occasions. Urine: No glycosuria; urobilinuria present. Faeces: Well-marked steatorrhoea and creatorrhoea. Occult blood, negative. Remarks : A permanent biliary fistula present. Patient died two years after operation-much wasting.

Case 4. J. H. P., male. Diagnosis: Chronic pancreatitis. Urine : Glycosuria. Cammidge test negative. Faeces : Well-marked steatorrhoea. Occult blood absent. Remarks : A case showing clinically chronic pancreatitis of long standing.

Case 5. H., female. Diagnosis: Chronic pancreatitis. Urine: Sugar absent. Cammidge test negative. Faeces: Steatorrhoea. Creatorrhoea. Occult blood absent. Remarks : An old case diagnosed by the appearance and character of the stools.

Case 6. N., male. Diagnosis: Chronic pancreatitis. Operation. Urine: Cammidge test negative. Faeces: Steatorrhoea and creatorrhoea. Occult blood absent. Remarks: Recovery,

Case 7. P. C., male. Diagnosis: Chronic pancreatitis? Carcinoma of head of pancreas. Operation. Urine : No glycosuria ; indicanuria present. Cammidge test negative. Faeces: Creatorrhoea, but no steatorrhoea. Remarks : Recovered. The possibility of the hard pancreas found at operation being inflammatory in nature was considered.

Case 8. J. B. J., male, aged 47. Diagnosis : Chronic pancreatitis; persistent diarrhoea. Diastase in Urine: 50 units. Faeces: Steatorrhoea and creatorrhoea, also starch granules. Remarks : Discharged from hospital, and died shortly afterwards.

Case 9. J. T., male, aged 60. Diagnosis: Chronic pancreatitis; pyloric obstruction. Operation. Loewi test: negative. Urine: No sugar; indicanuria present. Cammidge test negative. Faeces: No abnormality discovered. Test meal : showed slight hyperchlorhydria. Remarks : After operation patient recovered. The pancreas was found to be hard and enlarged.

Case 10. L.J., female. Diagnosis : Chronic pancreatitis. Operation. Diastase in urine: 22.2 units, after operation 10 units. Loewi test: negative. Urine: Sugar present, but later disappeared; traces of albumin. Blood sugar: $0.170 \mathrm{grm}$. per cent. Remarks : A hard pancreas found. No gall-stones felt.

Case 11. C. C., female, aged 54. Diagnosis: Cirrhosis of liver. ?Chronic pancreatitis. No operation. Loewi test: negative. Urine: No glycosuria; indicanuria present. Cammidge test negative. Faeces: Clay-coloured. Schmidt-Kashiwado test. Negative. Remarks: Jaundice and abdominal pain. Discharged improved.

Case 12. H. T., male, aged 29. Diagnosis: Chronic diarrhoea, six months' history. Diastase in urine : 200 and 250 units. Loewi test : positive (twice). Urine: No glycosuria. Cammidge test negative. Faeces: No excess of fat. Remarks: Patient improved on 
pankreon, and left hospital. There was a lowered glucose tolerance and steatorrhoea after a diet rich in fat, and the oil-test meal showed a diminished tryptic activity.

Case 13. C. K., female, aged 40. Diagnosis: Recurring jaundice. Chronic duodenal ulcer with adhesions probably involving the pancreas. Loewi test: positive. Urine: No glycosuria. Cammidge test negative. Faeces: No excess of fat. Remarks : There was the possibility of slight chronic pancreatitis in this case, but not proven.

Case 14. S., female. Diagnosis: Chronic pancreatitis. Diastase in urine: 300 units. Loewi test: positive. Urine: Sugar present, and persisted. Remarks: Severe abdominal pain, much wasting. Died in three months from wasting and exhaustion.

Case 15. P., male, aged 50. Diagnosis: Chronic pancreatitis. Operation. Diastase in urine: 50 units. Loewi test: positive. Urine: Glycosuria. Faeces: Steatorrhoea and creatorrhoea. Occult blood absent. Remarks : Diagnosed by operation, and died subsequently in an infirmary.

Case 16. Male. Diagnosis: Chronic pancreatitis. Diastase in urine: 1,000 units, then 50 units, finally 25 units three months later. Urine: No glycosuria, no ethereal sulphates. Faeces: Steatorrhoea. No occult blood. Remarks: No operation, but clinically a typical case of chronic pancreatitis.

Case 17. C. B, male, aged 46. Diagnosis : Obstruction to common bile duct. ? Chronic pancreatitis. ? Carcinoma of head of pancreas. Operation. Diastase in urine: 50 units. Urine: Sugar absent, bile pigments present. Faeces: Clay-coloured. Fat content of biliary type. Remarks: Cholecystoduodenostomy in 1914. Pancreas found to be hard and enlarged. Alive in 1917, but complained of abdominal pain, and a lump could be felt in the region of the pancreas.

Case 18. K. D., female, aged 37. Diagnosis: Appendix abscess. General pelvic inflammation. Diastase in urine : 100 units. Loewi test : negative. Urine: Glycosuria one day only. Remarks: Operation appendicectomy. Pancreas under suspicion.

Case 19. E. E., female, aged 58. Diagnosis : Obstructive jaundice. Chronic pancreatitis. Urine : Sugar absent. Cammidge test positive. No oxalate crystals. Faeces: Clay-coloured, urobilin absent, no steatorrhoea. Remarks: Gall-stones removed 10 years previously. Operation for cholecystostomy, and pancreas found to be hard.

Case 20. W. B., male, aged 36. Diagnosis: Cirrhosis of liver. Hepatitis. ?Chronic pancreatitis. Diastase in urine : 33.3 units. Loewi test : positive, but twice negative later. Urino: No glycosuria. Cammidge test negative. Faeces: Nil abnormal found. No steatorrhoea. Occult blood absent. Remarks : A lowered glucose tolerance was observed, but no laevulosuria followed the administration of 25 grams.

Case 21. D. T., male, aged 56. Diagnosis : Chronic pancreatitis; glycosuria. Diastase in urine: 50 units. Loewi test : positive. Urine : Glycosuria present, indicanuria present. Faeces: Steatorrhoea. Urobilin present. Occult blood absent. Remarks: History of wasting, epigastric pain, pain in the back and in right shoulder, and the passage of fatty stools.

Case 22. B. L.C., male, aged 40. Diagnosis: Chronic pancreatitis. Diastase in urine : 100 units. Urine : No glycosuria. Faeces: Normal. Remarks : Operation 8 years previously, and chronic pancreatitis found. Attacks of acid gastric dyspepsia since. No hyperglycaemia found.

Case 23. E. C., female, aged 58. Diagnosis : Chronic pancreatitis; obstructive jaundice. Urine: Sugar absent. Cammidge test positive. Faeces: Clay-coloured; urobilin absent. No excess of fat found. Remarks : 10 years previously operation for removal of gall-stones, and pancreas found to be hard.

Case 24. T. L., male. Diagnosis: Chronic pancreatitis. Diastase in urine: 50 units. Loewi test: positive. Urine: No glycosuria. Faeces: Steatorrhoea. Urobilin present. Remarks: Operation; also long history of the passage of fatty stools.

Case 25. M. R., female, aged 40. Diagnosis : Retroperitoneal haemorrbage. Operation. Post-operative pancreatitis. Diastase in urine: 33.3 units (2 days before operation), 50 units (4 days after operation). Loewi test: negative. Urine: No glycosuria. Faeces: Occult blood present. Remarks: Operation. No cause for haemorrhage found. Pancreas appeared normal, but incised, and drainage of head of pancreas. No fat necrosis. Recovered.

Case 26. S. B. male, aged 50. Diagnosis: Chronic pancreatitis. Duodenal ulcer. 
Diastase in urine: 128 units. Loewi test: negative. Urine: No glycosuria. Faeces: Oceult blood present. Remarks : Abdominal pain of 2 years' duration. Operation.

Case 27. S. P., male, aged 50. Diagnosis: General peritonitis. Diastase in urine: 100 units on two occasions. Loewi test: positive on both eyes. Urine: No glycosuria, but urobilinuria and indicanuria present. Remarks: Operation and autopsy. Pancreas appeared normal macroscopically. General peritonitis with adhesions found.

Case 28. D. G., female, aged 58. Diagnosis: Cholelithiasis; secondary pancreatitis. Loewi test: positive during jaundice, negative later. Urine: Glycosuria and urobilinuria. Faeces : Steatorrhoea. Total fat 60.5 per cent. Occult blood absent. Remarks : Improvement followed disappearance of jaundice.

\section{Carcinoma of Head of Pancreas.}

Case 1. C. N., male, aged 50. Diagnosis: Carcinoma of head of pancreas. Generalized secondary growths. Diastase in urine: 200 units. Loewi test : positive. Urine : Persistent glycosuria. Bile pigments present. Faeces: Creatorrhoea and steatorrhoea. Occult blood present. Test meal: Normal values for gastric contents. Remarks: Pancreas found at operation to be involved in a new growth. At autopsy the pancreas was apparently almost entirely replaced by new growth. There was an enlarged liver, venous thrombosis, and ascites.

Case 2. H. H., male, aged 50. Diagnosis: Carcinoma of stomach, adherent to pancreas. Diastase in urine: 100 units. Loewi test: negative. Urine: No glycosuria. Faeoes: No occult blood, but definite melaena later. Blood: Blood-sugar 0.12 grm. per cent. Remarks : Operation. Discharged I. S. Q.

Case 3. E. H. F., male, aged 60. Diagnosis : Carcinoma of ampulla of Vater. Interstitial hepatitis. Diastase in urine: 100 units. Urine: No glycosuria. Bile pigments present. Remarks: Abdominal pain and jaundice, with enlarged liver. Autopsy. Pancreas appeared normal. Growth proved to be a columnar-celled carcinoma.

Case 4. M. A. C., female, aged 62. Diagnosis : Carcinoma of pylorus involving head of pancreas. Urine: No glycosuria, no oxaluria. Cammidge test negative. Remarks: The pancreas at autopsy showed chronic inflammatory changes only.

Case 5. C. H., male, aged 53. Diagnosis : Carcinoma of head of pancreas. Diastase in urfne: 50 units. Loewi test: positive. Urine: Bile pigments present, no glycosuria. Faeces: No steatorrhoea, no urobilin. Occult blood absent. Remarks: Jaundice, enlarged liver and gall-bladder. Operation. Enlarged head of pancreas, distended common bile duct, no stones felt. Cholecystenterostomy performed. Autopsy. Hard pancreas infiltrated with columnar-celled carcinoma. Stricture of common bile duct found, probably primary growth.

\section{Diseases of the Liver.}

Case 1. T. D., male, aged 24. Diagnosis: Cirrhosis of liver. Chronic peritonitis. Diastase in urine: 10 units. Urine: Urobilinuria, no bile pigments or bile salts. Faeces: Nil abnormal. Remarks : At autopsy, cirrhosis of liver, chronic peritonitis, enlarged spleen, ascites. Pancreas normal.

Case 2. J. R., female, aged 45. Diagnosis : Cirrhosis of liver. Gall-stone in cystic duct. Streptococcal septicaemia. Diastase in urine: 10 units. Urine: Bile pigments present. Faeces: Pale-coloured stools, no steatorrhoea, urobilin present. Remarks: Ascites; diastase in ascitic fluid $=10$ units; lipase content, normal. Autopsy.

Case 3. C. C., male, aged 67. Diagnosis: Cirrhosis of liver. Recurring haemorrhagic ascites. Diastase in urine: 25 units. Loewi test: negative. Urine: No glycosuria. Remarks: Lowered glucose tolerance, between 25 and $50 \mathrm{grm}$. Autopsy.

Case 4. E. B. Diagnosis : Catarrhal jaundice. Diastase in urine: 50 units. Loewi test: negative. Urine: No glycosuria. Remarks: Jaundice disappeared with treatment.

Case 5. J. S., female, aged 49. Diagnosis : Catarrhal jaundice. Diastase in urine: 10 units. Urine: No glycosuria. Remarks: At operation, no cause for jaundice discovered.

Case 6. J. B., male, aged 37. Diagnosis : Transitory jaundice with transitory ascites. Diastase in urine: 33.3 units. Loewi test : negative. Urine: Urobilinuria. No glycosuria. Traces of bile pigment, no bile salts. Remarks: Patient cured. 
Case 7. F. J., female, aged 20. Diagnosis : Catarrbal jaundice. Diastase in urine : 33.3 units. Urine: No glycosuria. Urobilin present. Remarks: Jaundice, vomiting, and constipation. Cured.

Case 8. F., male, aged 55. Diagnosis: Transient jaundice with intermittent pyrexia. Diastase in urine: 32 units, Faeces: No steatorrhoea. Occult blood absent. Remarks: Discharged I. S. Q.

Case 9. K. H., female, aged 74. Diagnosis : Obstruction of common bile duct by tứmour. Gastric ulcer and cholangitis. Loewi test : negative. Urine: Bile pigments. No glycosuria. Cammidge test negative. Faeces: Clay-coloured stools, urobilin absent. Remarks: Autopsy. Pancreas normal on section. Gastric uleer showed inflammatory changes and also new growth.

Case 10. E. N., female, aged 39. Diagnosis : Empyema of gall-bladder. Urine: No glycosuria. Urobilinuria and indicanuria well marked. Cammidge test negative. Faeces: No steatorrhoea. Urobilin present. Occult blood absent. Test meal: Normal values. Remarks: Operation : incision and drainage of gall-bladder. There was no lowered glucose tolerance. Sahli test positive.

Case 11. W. B., male, aged 61. Diagnosis: Jaundice. Enlarged liver and spleen. Adherent pericardium. Diastase in urine: 50 units (highly concentrated urine). Urine: Bile pigments and traces of albumin present. Fraeces: Clay-coloured, no steatorrhoea. Occult blood absent. Remarks: At autopsy pancreas proved to be normal.

Case 12. R. W., female, aged 37. Diagnosis: Enlarged liver, ascites, glycosuria. Diastase in urine: 8 units. Loewi test: negative. Urine: Glycosuria. Faeces: No steatorrhoea. Oecult blood absent. Remarks: Operation two years proviously, diagnosis of new growth of liver made.

Case 13. K. C., female, aged 42. Diagnosis: Cirrhosis of liver. Diastase in urine: 33.3 units. Urine: Bile pigments present. Faeces : Clay-coloured, no steatorrhoea. Urobilin present. Remarks: Operation : cholecystostomy. Autopsy: No enlargement of liver or gallbladder; pancreas normal.

Case 14. E. A., female, aged 52, Diagnosis: Intermittent jaundice. Perihepatitis; enlarged spleen. Diastase in urine: 22.2 units. Loewi test: negative. Urine: No glycosuria, but bile pigments present. Faeces: Pale-coloured stools, no steatorrhoea. Urobilin present. Remarks: Liver found to be dark coloured and lobulated, and the spleen enlarged.

Case 15. M. D., female, aged 25. Diagnosis : Jaundice. Diastase in urine: 50 units. Loewi test : positive. Jrine: No glycosuria, but bile pigments and acetone bodies present. Remarks : Abdominal pain, vomiting, jaundice. Operation; no cause found, and pancreas appeared normal.

Case 16. J. F., male, aged 70. Diagnosis: Jaundice, biliary colic. Diastase in urine: 33.3 units. Loewi test: positive. Urine: Bile pigments present. Faeces: No occult blood. Test meal: No free hydrochloric acid present. Remarks: Loss of weight, and vomiting. Operation; no cause found, and pancreas appeared normal.

Case 17. T. M., male, aged 68. Diagnosis: Carcinoma of liver. Occlusion of bile passages; old pleural and peritoneal adhesions. Diastase in urine : 20 units. Loewi test: positive. Urine: No glycosuria. Faeces: Clay-coloured. Remarks : At autopsy no primary lesion found; pancreas normal.

Case 18. B., male. Diagnosis: Carcinoma of liver and bronchial glands, also deposits in ribs. Chronic interstitial nephritis. Diastase in urine: 33.3 units. Urine : Glycosuria. Traces of albumin. Blood: Sugar content $=0.22 \mathrm{grm}$. per cent. Remarks : Autopsy. The pancreas showed numerous small patehes like fat necrosis which had become fibrosed.

Case 19. E., male, aged 67. Diagnosis: Carcinoma of gall-bladder or ducts. Secondary deposits in liver. Diastase in urine : 50 units. Loewi test: negative. Remarks : Clinical diagnosis; no autopsy allowed.

Case 20. J. H., male. Diagnosis: Carcinoma of liver. Diastase in urine: 16 units. Urine: Bile pigments present. Faeces: Pale-coloured, pasty stools, showing excess of fatty acids and traces of urobilin. 


\section{Other Diseases.}

Case 1. R. W., female, aged 5. Diagnosis: Coeliac disease. Diastase in urine: 50 units, then 33.3 units. Urine: No glycosuria. Faeces: Typical pale-coloured fatty stool, showing excess of fatty acids.

Case 2. E. G., male, aged 3. Diagnosis : Coeliac disease. Diastase in urine: 32 units. Loewi test: negative. Urine: No glycosuria. Faeces : Steatorrhoea, with excess of fatty acids. Urobilin absent. Occult blood absent.

Case 3. S. W., female, aged 5. Diagnosis : Coeliac disease. Diastase in urine : 50 units. Faeces : Steatorrhoea. Urobilin present. Occult blood absent.

Case 4. G. P., male, aged 12. Diagnosis: Coeliac disease. Diastase in urine: 25 units. Loewi test: negative. Faeces: Pale-coloured frothy stool. Urobilin present. No steatorrhoea. Remarks: Abdominal pain, constipation, and pallor; distended and resonant abdomen; died; autopsy.

Case 5. F., female, 18 months. Diagnosis: Coeliac disease. Diastase in urine: 50 units. Urine: No glycosuria. Faeces : Pale-coloured stool, showing excess of fatty acids. Urobilin present in traces. No occult blood.

Case 6. T., female, aged 18 months. Diagnosis: Coeliac disease. Diastase in urine : 20 units. Urine: Sugar absent. Faeces : Pale-coloureä stool, showing excess of fatty acids. No occult blood.

Case 7. H. C., male, aged 6 years. Diagnosis: Congenital steatorrhoea. Diastase in urine : 10 units. Loewi test: negative. Urine: No glycosuria. Cammidge test positive. Faeces: Fixcess of undigested fat. Remarks: Case fully described by Garrod and Hurtley. Seen nine years later, and tests applied, but no evidence of pancreatic insulficiency found apart from the steatorrhoea.

Case 8. E., male, aged 2 years. Diagnosis: Congenital steatorrhoea. Diastase in urine : 25 units. Loewi test: negative. Urine: No glycosuria. Faeces: Steatorrhoea.

Case 9. A. P., female, aged 17. Diagnosis: Diabetes mellitus. Loewi test : negative. Urine : Glycosuria. Cammidge test negative. Sahli test negative. Remarks : At autopsy the pancreas appeared small, but otherwise no abnormality could be discovered either macroscopically or microscopically.

Case 10. Female. Diagnosis: Diabetes mellitus. Diastase in urine: 10 units. Urine : Glycosuria. Faeces: No steatorrhoea. Urobilin present. Remarks: Died in diabetic coma.

Case 11. J. B., female, aged 7 years. Diagnosis: Diabetes mellitus. Diastase in urine: 33.3 units. Urine: Glycosuria. Faeces: No steatorrhoea. Urobilin present. Remarks: Died in diabetic coma.

Case 12. D. W., male, aged 33. Diagnosis: Transient gly cosuria. Loewi test: negative. Urine: Glycosuria. Cammidge test negative. Glucose tolerance test showed a lowered glucose tolerance. Remarks: Slight restriction of carbobydarates in the diet removed the glycosuria. There was a history of duodenal nlcer two years previously.

Case 13. J. C., male, aged 44. Diagnosia : Diabetes mellitus. Urine : Cammidge test negative. Faeces: No steatorrhoea.

Case 14. R. M., male, aged 19. Diagnosis : Intermittent glycosuria. Urine: Glycosuria. Cammidge test negative. Faeces: No steatorrhoea. No occult blood. Remarks: No evidence of pancreatic origin of the glycosuria could be ascertained. When the glycosuria disappeared the patient tolerated 50 and $100 \mathrm{grm}$. of glucose without any signs of glycosuria.

Case 15. A. M., female, aged 33. Diagnosis : Glycosuria. Urine: Well-marked. glycosuria. Cammidge test negative. Faeces : No steatorrhoea. Remarks: No evidence of pancreatic insufficiency obtained.

Case 16. S. B., male, aged 52. Diagnosis: Diabetes mellitus. Diastase in urine: 50 units (volume of urine 2,700 c.c. for twenty-four hours). Loewi test: negative. Urine: Glycosuria. Remarks: Improved on dieting.

Case 17. F., female. Diagnosis: Diabetes mellitus, Diastase in urine: 10 units. Loewi test : negative. Urine: Glycosuria. 
Case 18. J. W. A., male, aged 29. Diagnosis: Diabetes mellitus. Diastase in urine: 10 units. Urine: Sugar present. Blood: Sugar content $=0.37$ grm. per cent. Remarks: History of two years' duration of glycosuria. Signs of diabetic coma.

Case 19. A. C. M., female. Diagnosis: Glycosuria. Diastase in urine: 22.2 units. Loewi test: negative. Urine: Sugar present three years previously, now absent. Faeces: Steatorrhoea. Occult blood present. Test meal : Hyperchlorhydria. Remarks; Epigastric pain. X-ray examination showed great distension of duodenum. 'l'he case was regarded as one of gastric ulcer and the pancreas under suspicion.

Case 20. C. C., male, aged 59. Diagnosis: Glycosuria. Diastase in urine: 25 units. Loewi test: negative. Urine: Sugar present. Remarks: Loss of weight, 15-8 stones, and possibility of pancreatic origin of glycosuria considered.

Case 21. H. J. H. S., male, aged 31. Diagnosis: Glycosuria. Diastase in urine: 50 units. Loewi test: negative. Urine: Pronounced glycosuria two years previously, now absent. Normal sugar tolerance. Remarks: Loss of weight. Pancreatic origin of the glycosuria considered.

Case 22. D. C. D., male. Diagnosis : Glycosuria. Diastase in urine : 25 units. Loewi test: negative. Urine: Glycosuria. Remarks: The glycosuria gradually disappeared on dietetic treatment.

Case 23. D. B., male. Diagnosis: Glycosuria and jaundice. Diastase in urine: 33.8 units. Loewi test: negative. Urine: Glycosuria. Fraeces: No steatorrhoea. Urobilin present. Remarks: Taundice disappeared, but gly cosuria persisted.

Case 24. F., female, aged 16. Diagnosis : Chronic colitis. Diastase in urine: 10 units. Loewi test: positive, but later negative. Urine: Sugar absent. Faeces: Pale-coloured stools, showing excess of fatty acids. Remarks: Infuntilism ? pancreatic.

Case 25. G. E., male, aged 49. Diagnosis: Abdominal pain, wasting. Diastase in urine : 20 units. Urine: Sugar absent. Faeces: Pale-coloured, but no steatorrhoea. Urobilin present. Remarks: Loss of weight, 11-9 stones. Diarrhoea. No cause discovered.

Case 26. E. A., female, aged 11. Diagnosis: Anorexia nervosa. Loewi test: negative. Urine: Sugar absent. Cammidge test negative. Faeces: No steatorrhoea. No occult blood. Remarks: Wasting, improvement on dieting.

Case 27. H. F., male, aged 54. Diagnosis: Carcinoma of pylorus. Loewi test : positive, later negative. Urine: No sugar. Cammidge test positive. Faeces: No steatorrhoea. Test meal: Suggested malignant disease of the stomach. Kashiwado's test negative. Remarks: At operation and autopsy the pancreas was found to be normal.

Case 28. W. P., male, aged 39. Diagnosis: Dilatation of stomach. Loewi test: negative. Urine: No glycosuria. Cummidge test negative. Faeces: No steatorrhoea. Occult blood present. Remarks: No cause for the dilatation of the stomach discovered. Improved after gastro-enterostomy.

Case 29. E. S., female, aged 63. Diagnosis: Careinoma of left breast. Secondary deposits in pituitary, pineal, and suprarenal glands. Diastase in urine: 10 units. Urine: No glycosuria. Faeees: No steatorrhoea. Urobilin present. Remarks: The pancreas appeared normal both macroscopically and microscopically. This result is of interest in view of the involvements of the other ductless glands.

Case 30. A. W., female, aged 45. Diagnosis: Carcinoma of the breast. Bronchitis. Urine: Sugar absent. Cammidge test negative. Freces: No steatorrhoea. Sahli test negative. Test meal : Normal values. Reraarks: No evidence of involvement of the pancreas.

Case 31. H. H., male, aged 50. Diagnosis: Carcinoma of testis. Secondary deposits in lumbar glands. Diastase in urine : 33.3 units. Loewi test : negative. Uxine: No glycosuria. Faeces: No steatorrhoea. Remarks : Large haemorrhagic tumour in epigastrium, thought to he pancreatic at operation, but at autopsy the pancrens proved to be normal. 